\title{
Electronic Materials Will Be Topic for Joint ICEM '94/MRS-ICA Meeting in Taiwan
}

The 1994 International Conference on Electronic Materials will be held jointly with the MRS-International Conference Asia on October 17 to 20, 1994 in Hsinchu, Taiwan, Republic of China. The combined conference is being organized by MRSTaiwan under the auspices of the International Union of Materials Research Societies (IUMRS), Otto C.C. Lin and LiChung Lee are conference chair and cochair, and L.J. Chen and J.M. Liu are chair and co-chair, respectively, of the technical program.

\section{Symposia Featured}

The program will include symposia on the following topics:

- Structural Characterization for

Electronic Materials

- Electronic Ceramics

- Sensor Materials

- Compound Semiconducting Materials

- ULSI Materials

- High $T_{c}$ Superconductors

- Materials Technology for Flat Panel Display

- Materials for Electronic

Interconnections and Packaging

- Recording Media
- Thin-Film Materials

Full length papers from these symposia will be published in Materials Chemistry and Physics (Elsevier Science Publishers).

\section{Call for papers}

Abstracts on the above subjects are currently being solicited. Authors are asked to submit five copies of an abstract $(1,000$ words maximum), with up to two additional pages of figures and drawings. Abstracts should be submitted before April 30, 1994 to the program chair:

L.J. Chen

c/o Materials Research

Laboratories, ITRI

Conference Department/ICEM '94

Bldg. 77, 195 Chung-hsing Road, Sec. 4

Chutung, Hsinchu 31025

Taiwan, ROC

Phone: 886-35-820064;

Fax: 886-35-820262 or

886-35-820247

Notices of acceptance will be sent by June 30, 1994.

\section{Registration}

Detailed information on the joint conference, including a pre-registration form and instructions for formatting abstracts and full papers, will be sent out in October 1993. The deadline for receiving a registration fee discount is August 31, 1994. Final registration must be made by September 15, 1994. For further information on the conference program, registration, and accommodations, please get in touch with the Secretariat at the address above.

\section{IUMRS Creates Lectureship}

The International Union of Materials Research Societies announces the establishment of the IUMRS Lectureship. IUMRS scholars will be selected to deliver lectures in developing countries. The Union will offer travel support of up to $\$ 1,200$, with hosting institutions providing living expenses.

Nominations for candidates for the 1993 Lectureship are being accepted until April 15, 1993. Those interested in applying should submit a personal vitae, three letters of recommendation, and a pledge of host institution support to R.P.H. Chang, Northwestern University, Department of Materials Science and Engineering, 2225 N. Sheridan Road, Evanston, IL 60208.

\section{SPECIAL NOTICE TO MRS MEMBERS:}

1993 Members of the Materials Research Society may subscribe to MATERIALS LETTERS for the special rate of $\$ 38$. You will receive Volumes 15, 16, 17 and 18.

MATERIALS LETTERS is an interdisciplinary journal affiliated with the Materials Research Society, devoted to the rapid publication of short communications on the science, applications and processing of materials.

Order your subscription today from: Materials Research Society 9800 McKnight Road, Pittsburgh, PA 15237 Phone: (412) 367-3003; FAX: (412) 367-4373
SALE! SALE! SALE! SALE! Save 30\% - 76\%

\section{with the MRS BOOK SALE! 88 Different Books}

All titles only $\$ 17.50$ and get 1 FREE with every 4 you buy!

Supplies are limited - for more information call (412) 367-3012 or circle reader service card No. 127 today! 